\title{
Swahili Language
}

National Cancer Institute

\section{Source}

National Cancer Institute. Swahili Language. NCI Thesaurus. Code C154145.

A Niger-Congo Bantu language spoken by the Swahili people throug hout eastern and south-eastern Africa. 